
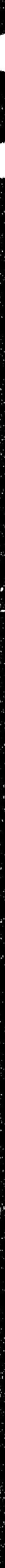

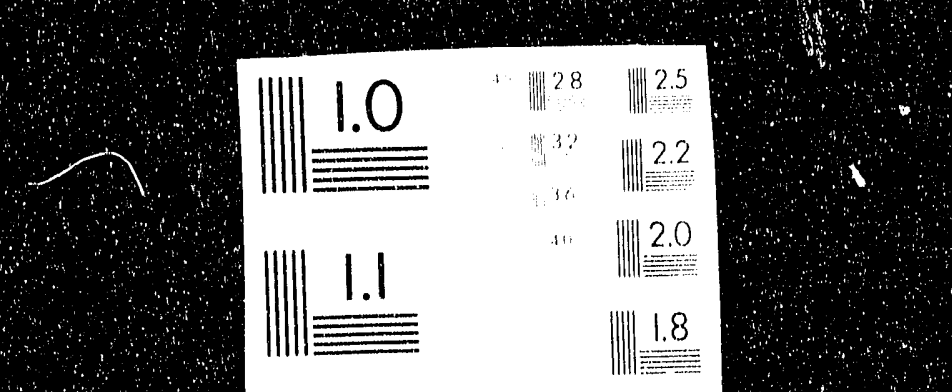

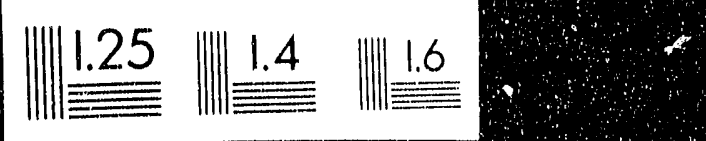
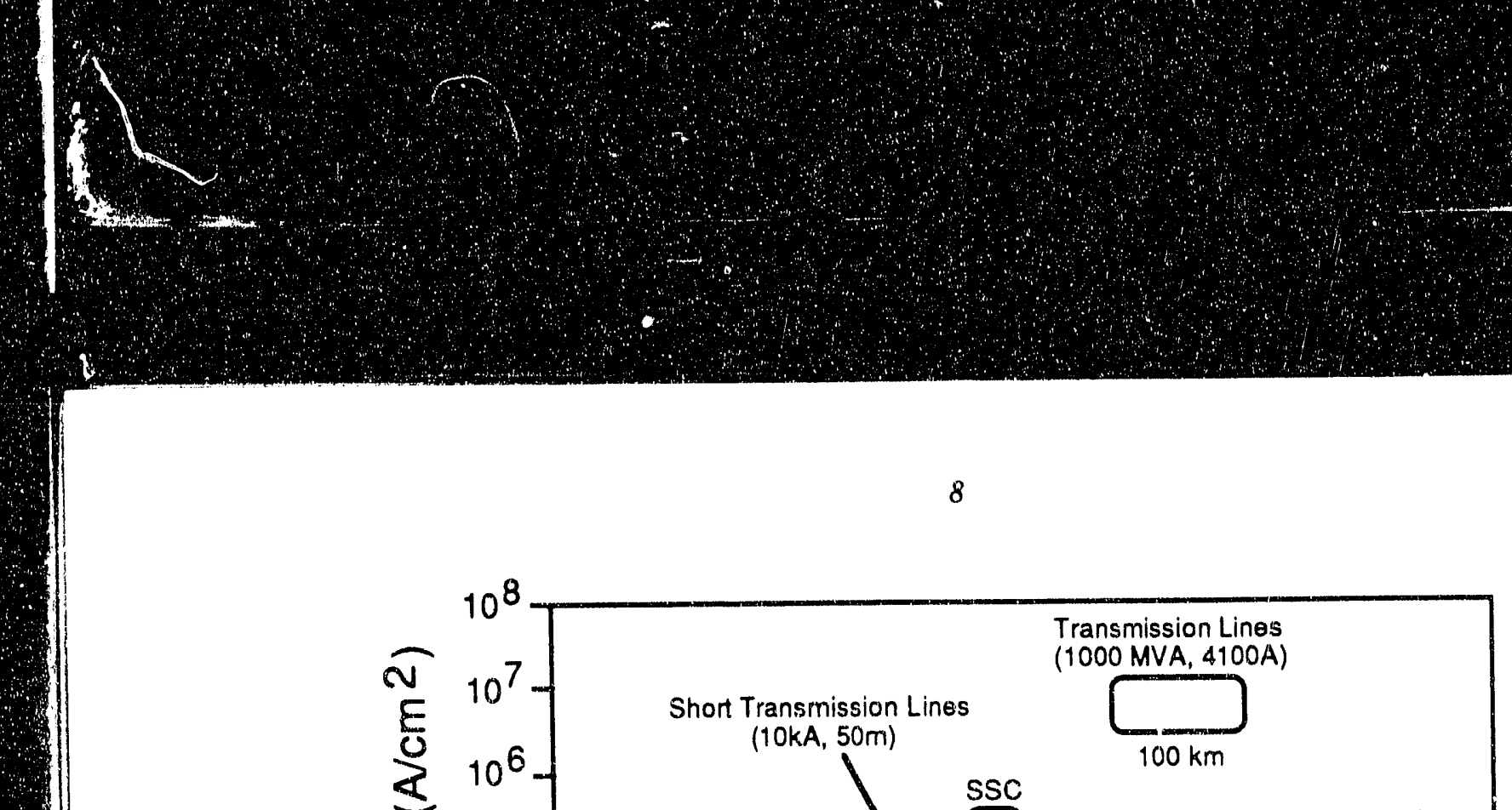
$2 / 7-429501$

\section{Potential Impact of High Temperature Superconductors on Maglev Transportation}

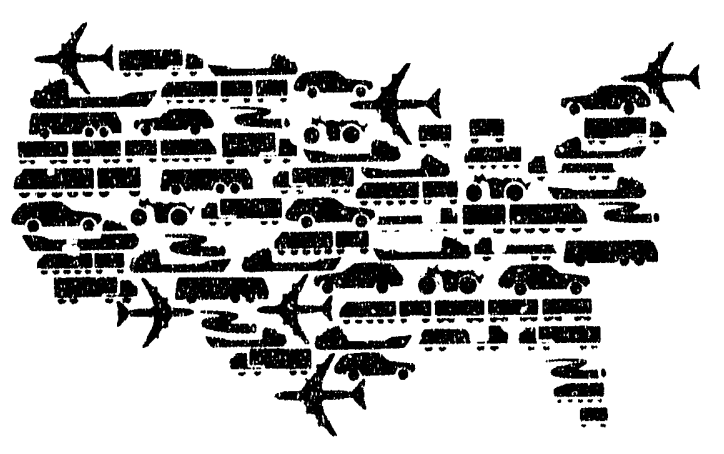

Center for Transportation Research Argonne National Laborator',

Operated by The Uriversity of Chango, under Contrart W-31-109-Eng.38, for the United States Department of Energy 


\section{Argonne National Laboratory}

Argonne National Laboratory, with facilities in the states of Illinois and Idaho, is owned by the United States govemment, and operated by the University

of Chicago under the provisions of a contract with the Department of Energy.

This technical memo is a product of Argonne's Energy Systems (ES)

Division. For information on the division's scientific and engineering activities, contact:

Director, Energy Systems Division

Argonne National Laboratory

Argonne, Illinois 60439-4815

Telephone (708) 252-3724

Presented in this technical memo are preliminary results of ongoing work or work that is more limited in scope and depth than that described in fornal reports issued by the ES Division.

\section{Disclaimer}

This report was prepared as an account of work sponsored by an agency of the United States Govemment. Neither the United States Govemment nor any agency thereof, nor any of their employees, makes any warranty, express or implied, or assumes any legal liability or responsibility for the accuracy, completeness, or uselulness of any information, apparatus, product, or process disclosed, or represents that its use would not intringe privately owned rights. Reference herein to any specific commercial product, process, or service by trade name, trademark, manulacturer, or otherwise, does not necessarily constitute or imply its endorsement, recommendation, or favoring by the United States Govemment or any agency thereof. The views and opinions of authors expressed herein do not necessarily state or reflect those of the United States Govemment or any agency thereof. 


\title{
Potential Impact of High Temperature Superconductors on Maglev Transportation
}

\author{
by J.R. Hull*
}

Center for Transportation Research, Energy Systems Division,

Argonne National Laboratory, 9700 South Cass Avenue, Argonne, Illinois 60439

\section{February 1992}

Work sponsored by United States Army Corps of Engineers

"Hull is affiliated with the Materials and Components Technology Division.

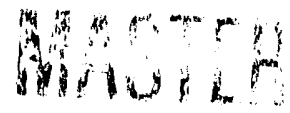




\section{Contents}

Acknowledgments............................................................ v

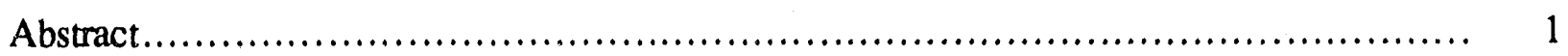

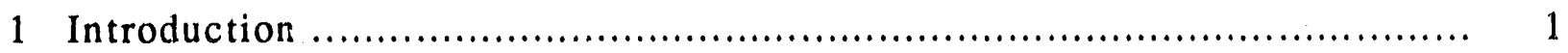

2 Development of High-Temperature Superconductors $\ldots \ldots \ldots \ldots \ldots \ldots \ldots \ldots \ldots \ldots \ldots \ldots$

2.1 Families of High-Temperature Superconductors............................. 4

2.2 Development Plan ....................................................... 6

2.3 Current Status of HTS Technology .......................................... 6

2.4 Technical Challenges of HTS Technology .................................... 8

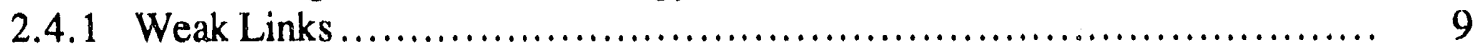

2.4.2 Flux-Flow Resistance .............................................. 9

2.4 .3 Mechanical Strength ................................................. 10

2.4.4 Thermal-Magnetic Stability ............................................ 11

2.5 Near-Term Applications ..................................................... 13

2.6 Intermediate-Term Applications ........................................ 14

3 Potential Areas of Impact for Maglev Transportation ......................... 15

3.1 Liquid-Nitrogen-Cooled Superconducting Magnets ......................... 15

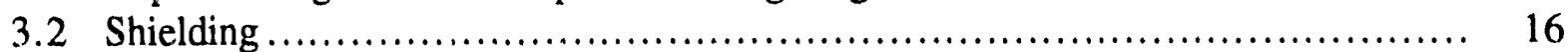

3.3 Superconducting Magnetic Energy Storage for Wayside Power ................. 16

3.4 Flywheels for Wayside Power ............................................. 16

3.5 Downleads to Continuously Powered Magnets ............................... 17

3.6 Liquid-Hydrogen-Cooled Magnets ...................................... 17

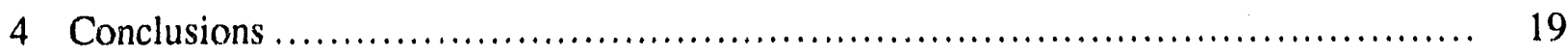

References............................................................. 20

Figures

1 Critical Surface for the Existence of Superconductivity ........................... 3

2 Historical Development of Record Critical Temperatures in Superconductors ............ 4

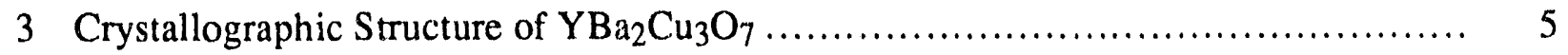

4 Development Plan for High-Temperature Superconductors ........................ 6 


\section{Figures (Cont'd)}

5 Critical Current Density as a Function of Magnetic Field for State-of-the-Art Superconductors, Showing Requirements for Various Applications.....

6 Critical Current Density as a Function of Volume Performance Factor for State-ofthe-Art Superconductors, Showing Requirements for Various Applications

7 Magnetic Field as a Function of Temperature for Several HTSs, Denoting the Boundary at which Flux-Flow Problems Occur

8 Specific Energy for Frictional Heating and Cracking Disturbances as a Function of Magnetic Field Strength with Comparison of Specific Heat, Latent Heat, and Conductor Temperature Rise...

9 Schematic Diagram of Fluid and Electricity Flow in the Liquid-Hydrogen Maglev System 


\section{Acknowledgments}

This work was performed under the auspices of the U.S. Army Corps of Engineers in accordance with the Military Interdepartmental Purchase Request \#E8691R001 to the U.S. Department of Energy, Assistant Secretary for Conservation and Renewable Energy, Office of Transportation Technologies. The author has benefited from numerous conversations with $\mathrm{H}$. Coffey, J. He, L. Johnson, T. Mulcahy, D. Rote, and T. Rossing of the ANL maglev group. The author is grateful for many useful review comments from R. Boom and M. Hilal of the University of Wisconsin Applied Superconductivity Center and from R. Armstrong, J. Matthews, and R. Suever of the U.S. Army Corps of Engineers, Huntsville Division. A special acknowledgment is given to F. Moon of Cornell University, who shared many excellent thoughts with the author. 


\title{
Potential Impact of High-Temperature Superconductors on Maglev Transportation
}

\author{
by
}

John R. Hull

\begin{abstract}
This report describes the potential impact that high-temperature superconductors (HTSs) may have on transportation by magnetically levitated vehicles. It is not intended as a planning document, but rather as an overview of potential HTS applications to magnetic-levitation (maglev) transportation. The present maglev program in the United States is summarized, and the present status of development of HTSs is described. Areas identified for possible impact on maglev technology are (1) liquid-nitrogen-cooled levitation magnets, (2) magneticfield shielding of the passenger compartment, (3) superconducting magnetic energy storage for wayside power, (4) superconducting bearings for flywheel energy storage for wayside power, (5) downleads to continuously powered liquid-heliumcooled levitation magnets, and (6) liquid-hydrogen cooled levitation magnets and linear motor propulsion windings. Major technical issues that remain to be resolvet for the use of HTSs in maglev applications include thermal magnetic stability, mechanical properties, and critical current density at liquid-nitrogen temperatures.
\end{abstract}

\section{Introduction}

The possibility of supporting a vehicle by magnetic icrces has been discussed since the early part of this century. Over the past several years, a number of countries have devoted considerable resources to develop a high-speed ground transportation system in which a vehicle, magnetically levitated a short distance over a guideway, travels at high speed without physically contacting any supporting structure.

Magnetic-levitation (maglev) transportation is most often envisioned as providing city-tocity transportation over distances up to $900 \mathrm{~km}$ at speeds up to $500 \mathrm{~km} / \mathrm{h} .^{1}$ A potential market for maglev transportation is in replacing airplanes on the short- to medium-distance routes that connect smaller cities to the nation's major hub airports. ${ }^{1}$ Substituting maglev vehic!es for aircraft on these routes would increase the capacity of existing airports, while reducing noise and air pollution. Because airplanes are most energy-efficient when traveling over long distances, using the electrically propelled maglev vehirles on the shorter-distance trips would save fuel and decrease the nation's dependence on imported petroleum. Travel time using a maglev vehicle would probably be shorter than if traveling by airplane on such short-distance trips because boarding time would be mininal, and there would be no delays caused by aircraft congestion on the ground or in the air. 
Although adverse weather could affect maglev vehicle operation, only the most severe weather conditions, such as hurricanes, are expected to prevent maglev vehicles from operating.

Maglev development began more than two decades ago in the United States, Germany, Japan, Canada, and England. By 1974, Ford Motor Company was developing a $500-\mathrm{km} / \mathrm{h}$ test sled for the evaluation of one maglev technology. In 1975, however, recognizing the transportation capabilities of (then) new wide-body jet aircraft and facing conflicting demands for federal funding to improve the railway system, the United States government withdrew funding for these studies. Efforts continued in Japan and Germany.

The first prototypes of commercial maglev systems should begin operation in the next few years. Today, Germany is in the final stages of evaluating the safety of its electromagnetic system, a $22-\mathrm{km}$ demonstration of which will be operational in Orlando, Florida, by 1994. Japan expects to demonstrate one of its designs in Sapporo, Japan, by the same time. Each country has invested over $\$ 1$ billion in its respective technology. A $\$ 5.2$ billion bid has been submitted to install a German-developed system between Las Vegas, Nevada, and Anaheim, California, at a cost of more than $\$ 12$ million per kilometer.

The Congress has taken note of these developments, and several maglev-related bills have been introduced. Twelve million dollars was appropriated for maglev studies in fiscal year (FY) 1991. A National Maglev Initiative (NMI), led by the Federal Railroad Administration and codirected by the U.S. Department of Energy and the Army Corps of Engineers, was formed to assess maglev technologies and recommend a course of action for the United States. The Corps of Engineers received $\$ 8.0$ million, and the U.S. Department of Transportation received $\$ 12.0$ million, for maglev studies in FY 1992. The following options for the NMI were identified:

1. Install the German system,

2. Modify and codevelop either the German or Japanese system, or

3. Develop a new system.

Exercising either the second or third option may require that new means of magnetic levitation be conceived and analyzed.

Superconductivity is a technology that has many possible applications in the transportation sector, including use in maglev systems. ${ }^{2}$ Since 1987 , a number of ceramic materials have been discovered that superconduct at temperatures above $77 \mathrm{~K}$, the boiling temperature of nitrogen at 1 -atm pressure. These high-temperature superconducting materials hold exciting potential for such applications as use in maglev systems because the cooling of objects to liquid-nitrogen temperature is considerably more reliable and about 20 times less expensive than cooling objects to liquidhelium temperature. As yet, no practical wires have been fabricated from these new hightemperature superconductors, but considerable research and development is being devoted toward this end, and it is generally believed that commercially useful wires will be forthcoming in the next several years. ${ }^{3}$ 


\section{Development of High-Temperature Superconductors}

Superconductivity is the name given to a combination of electric and magnetic properties that appears in certain materials when they are cooled to low temperature. One of the most useful of these properties is the complete absence of electrical resistivity to the flow of direct current, making possible very large current densities without the generation of heat. In commercially available superconducting wire, it is now possible to obtain current densities of more than $1000 \mathrm{~A} / \mathrm{mm}^{2}$. This is equivalent to continuously sending a lightning bolt through a conductor having a diameter no bigger than a pencil. Superconducting wires of this type can be used to create very powerful magnets. ${ }^{4}$

In order for the superconducting state to exist, the material must be kept below a critical temperature $\left(\mathrm{T}_{\mathrm{c}}\right)$ and a critical magnetic field $\left(\mathrm{H}_{\mathrm{c} 2}\right)$, as shown in Figure 1. Every superconducting

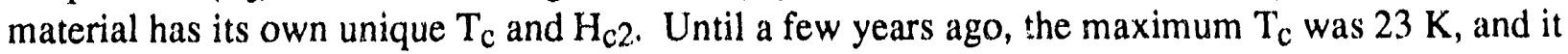
was generally believed that all practical superconductors would need to operate at $4 \mathrm{~K}$ (equivalent to $-269^{\circ} \mathrm{C}$ ) in liquid helium. At present, liquid helium is used to keep the superconductors cold in all superconductivity-based applications, such as magnetic resonance imaging, accelerator

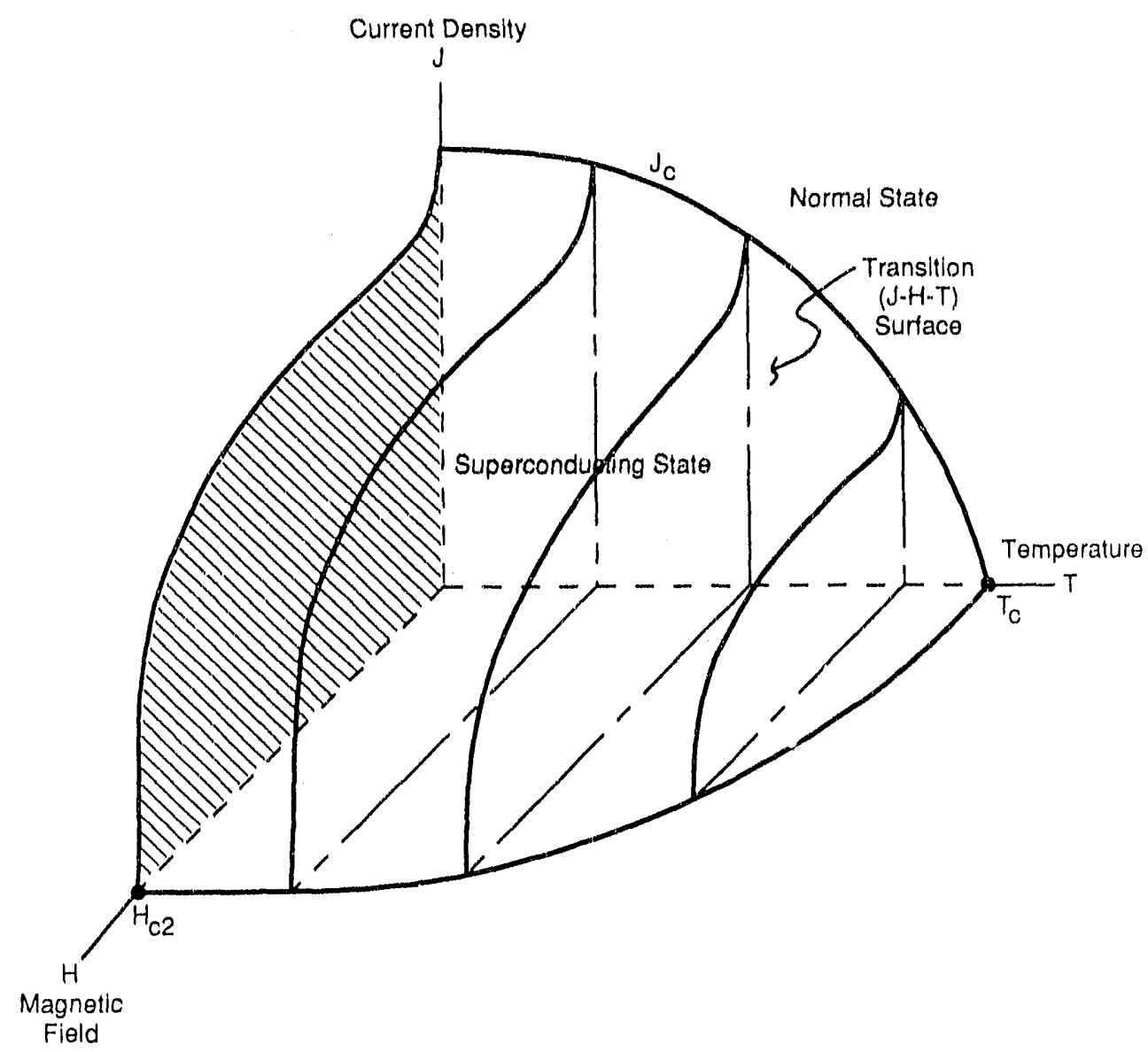

FIGURE 1 Critical Surface for the Existence of Superconductivity 
magnets, and the superconducting magnets used in some of the present prototype maglev vehicles. In all practical superconductors, the superconducting state is also limited by a bounding critical current density $\left(\mathrm{J}_{\mathrm{C}}\right)$, which is a function of temperature $(T)$ and magnetic field $(\mathrm{H})$ (as is also shown in Figure 1), as well as by the means of superconductor fabrication.

\subsection{Familles of High-Temperature Superconductors}

The first announcement of a superconducting material with a $\mathrm{T}_{\mathrm{c}}$ above $77 \mathrm{~K}$ was in 1987.5 Shortly thereafter, several other materials were discovered with even higher values of $\mathrm{T}_{c}$, and the present accepted maximum is $125 \mathrm{~K} .{ }^{6}$ The sharp jump in the maximum $\mathrm{T}_{\mathrm{c}}$ possible, as shown in Figure 2, caused considerable excitement in the scientific and technical community. Collectively, the supercondirtors with $\mathrm{T}_{\mathrm{c}}$ greater than about $64 \mathrm{~K}$ (the boiling point of nitrogen under a vacuum) are called high-temperature superconductors (HTSs). Some researchers include materials with $T_{0}$ values as low as $30 \mathrm{~K}$ in this class, because these are distinctly different from the conventional classes of superconductors known prior to 1987.

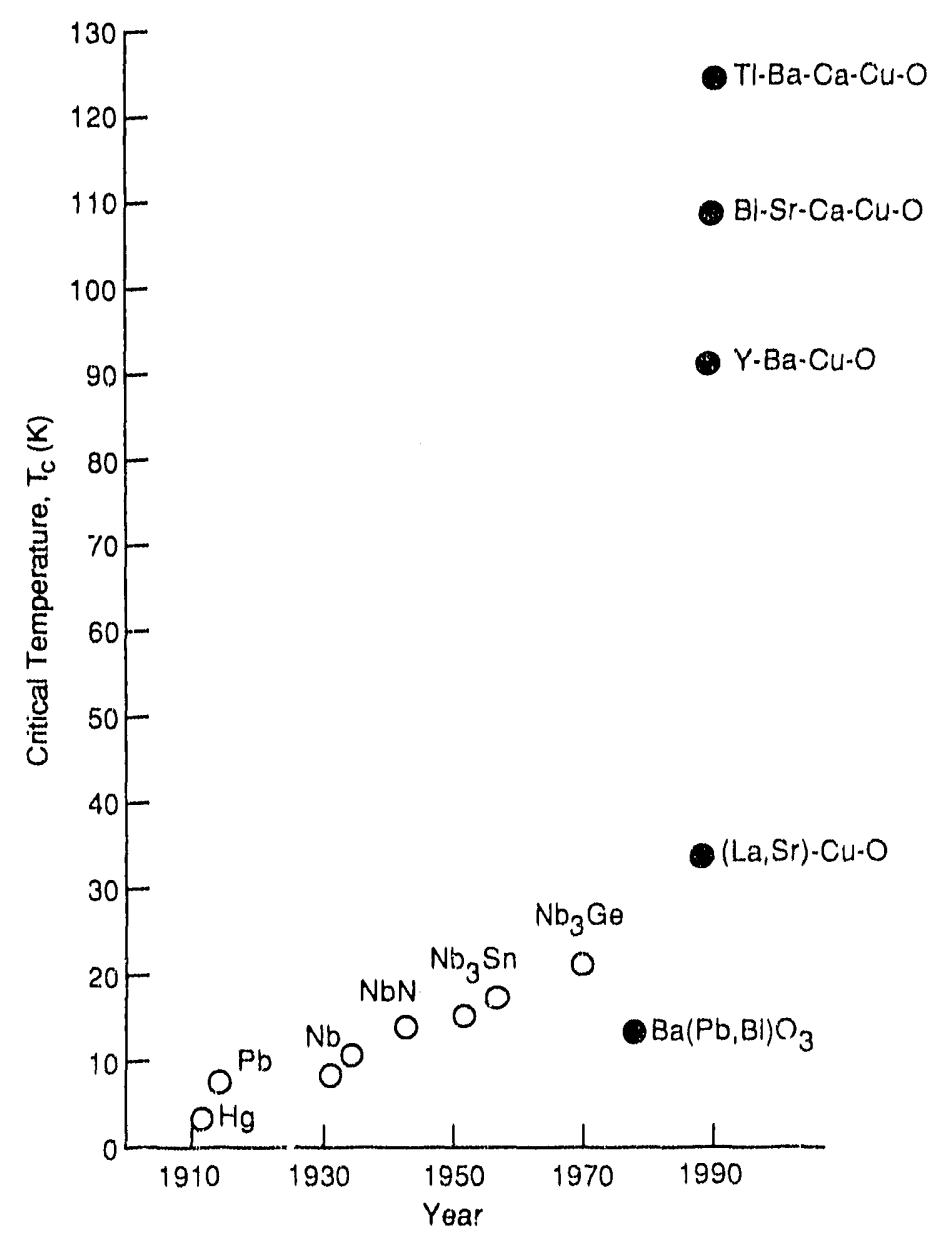

FIGURE 2 Historical Development of Record Critical Temperatures in Superconductors 
All of the HTSs presently under investigation for practical applications are copper oxides. In contrast with the conventional metallic and intermetallic low- $\mathrm{T}_{\mathrm{c}}$ superconductors already in use, the new HTSs are ceramics. T'hese compounds are highly anisotropic in that the superconducting currents tend to flow in planes formed by the copper oxides, whereas flow perpendicular to these planes is difficult. There are three major families of HTSs. The nomenclature is not totally consistent from researcher to researcher, but a common scheme of abbreviation denotes the families as YBCO, BSCCO, and TBCCO, based on the initial letters of the elements present.

The first HTS discovered was $\mathrm{YBa}_{2} \mathrm{Cu}_{3} \mathrm{O}_{7-x}$ of the YBCO family, where the subscript $\mathrm{x}$ denotes an amount less than unity. ${ }^{5}$ The oxygen content in any HTS may vary somewhat, but this variation usually plays a minor role in determining details of the physical properties. The crystallographic structure for members of the YBCO family is shown in Figure 3. It was soon discovered that this YBCO compound could also take the form $\mathrm{REBa}_{2} \mathrm{Cu}_{3} \mathrm{O}_{7-x}$, where $\mathrm{RE}$ denotes rare earth. The critical temperatures of these compounds vary by several degrees around $92 \mathrm{~K}$, depending on the rare earth present. Most rare earths will form a superconducting compound in the YBCO family; however, praseodymium, cerium, and terbium do not. $\mathrm{REBa}_{2} \mathrm{Cu}_{3} \mathrm{O}_{7-\mathrm{x}}$ is of ten called the 123 phase, after the subscripts for the first three elements. The 123 phase has been the fucus of most of the research effort so far in HTS development. There is also a 124 YBCO phase, with a $\mathrm{T}_{\mathrm{c}}$ of about $80 \mathrm{~K}$, as well as a $247 \mathrm{YBCO}$ phase.

Compounds in the second HTS family, the BSCCO family, contain bismuth, strontium, calcium, copper, and oxygen. ${ }^{7}$ Sometimes lead is partially substituted for the bismuth, which seems to simplify the formation of pure phases. There are two important phases of BSCCO: the 2212 compound, with a $\mathrm{T}_{\mathrm{c}}$ of about $80 \mathrm{~K}$, and the 2223 compound, with a $\mathrm{T}_{\mathrm{c}}$ of about $105 \mathrm{~K}$.

Compounds in the third family, the TBCCO family, contain thallium, barium, calcium, copper, and oxygen. This family has many phases with high critical temperatures. ${ }^{8}$ Initially, the TBCCO family did not receive as much attention as the other two families, mainly because of the difficulty of working with the volatile and somewhat toxic thallium. At this time, however, research in the TBCCO family is receiving high priority because of some recent discoveries that are discussed later in this report.

Another class of HTSs incorporates $\mathrm{KBiO}_{3}$ and has a $\mathrm{T}_{\mathrm{c}}$ of $32 \mathrm{~K} .{ }^{9}$ This class also consists of ceramic compounds, but it differs from the three copper oxide families in

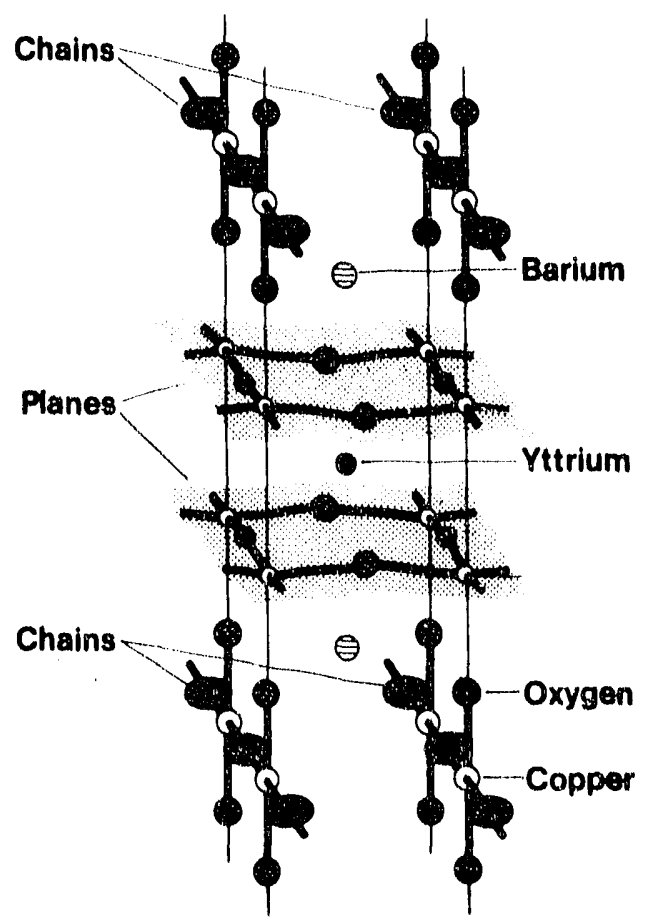

FIGURE 3 Crystallographic Structure of $\mathrm{YBa}_{2} \mathrm{Cu}_{3} \mathrm{O}_{7}$ 
that it is isotropic. So far, there is some interest in this compound for electronic applications, but not for making high-current-density wires.

A recently discovered family of superconductors incorporates the compound $\mathrm{C}_{60}$, which takes the approximate shape of a soccer ball. When properly doped with cesium and rubidium, this organic superconductor has reached a $T_{c}$ as high as $28 \mathrm{~K} .10,11$ So far, the superconducting organic compounds are of scientific value only. Although there is considerable enthusiasm for possible applications of such superconductors, transport critical currents have yet to be measured, and the potential is not yet quantified.

\subsection{Development Pian}

A worldwide effort is now under way to develop HTSs into forms that can be used in commercial products. The research and development program at Argonne National Laboratory, which at present has the largest publicly funded superconductivity program in the United States, is summarized in Figure 4. Although most people believe that commercial products eventually will be realized, further development must take place before superconductive materials become useful for widespread applications, such as superconducting magnets for maglev vehicles.

\subsection{Current Status of HTS Technology}

Progress in the development of HTS wires has been rapid since the initial discovery of HTS materials; so far, however, there is no known method for producing HTS wire that will be useful in a maglev magnet operating at $77 \mathrm{~K}$. The major obstacle is critical current density, $\mathrm{J}_{\mathrm{C}}$, at high magnetic field strength. The value of $\mathrm{J}_{\mathrm{c}}$ as a function of magnetic field for several HTS samples is shown in Figure 5, along with the requirements for some typical potential superconducting applications. Figure 6 shows that in cases where good $\mathrm{J}_{\mathfrak{c}}$ has been produced, only short lengths can be fabricated. Experience with low-temperature superconductor (LTS)

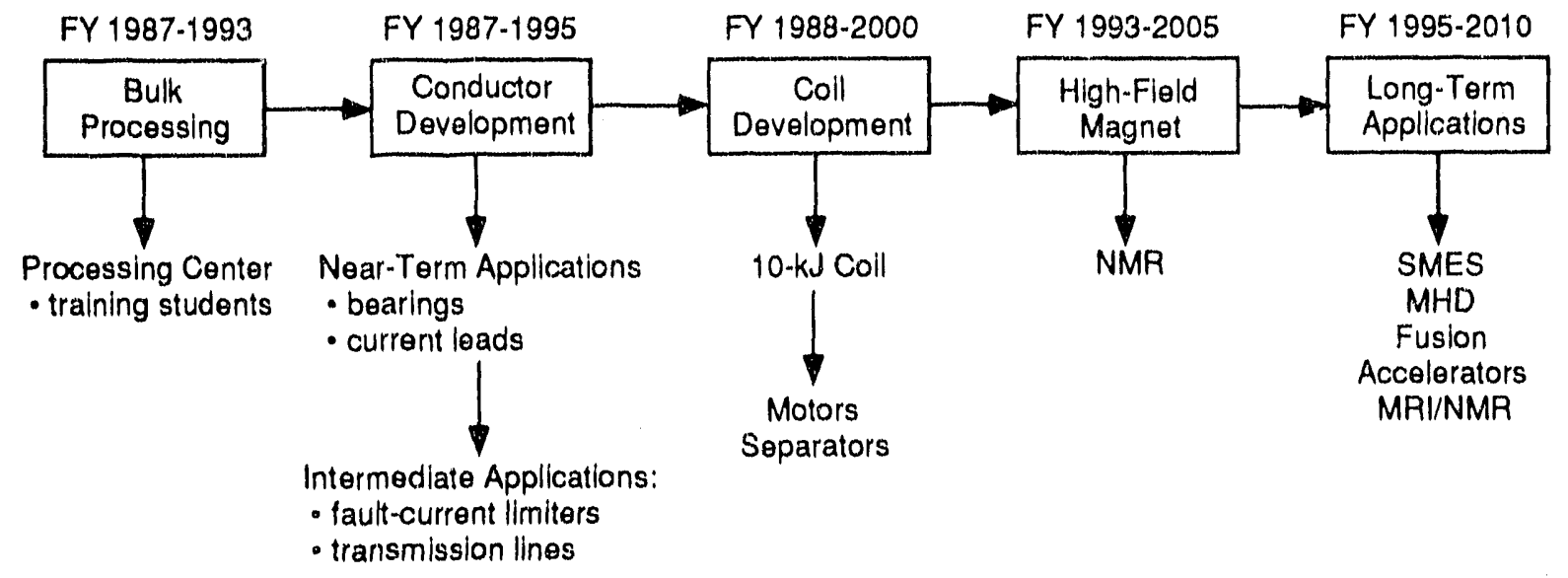

FIGURE 4 Development Plan for High-Temperature Superconductors 


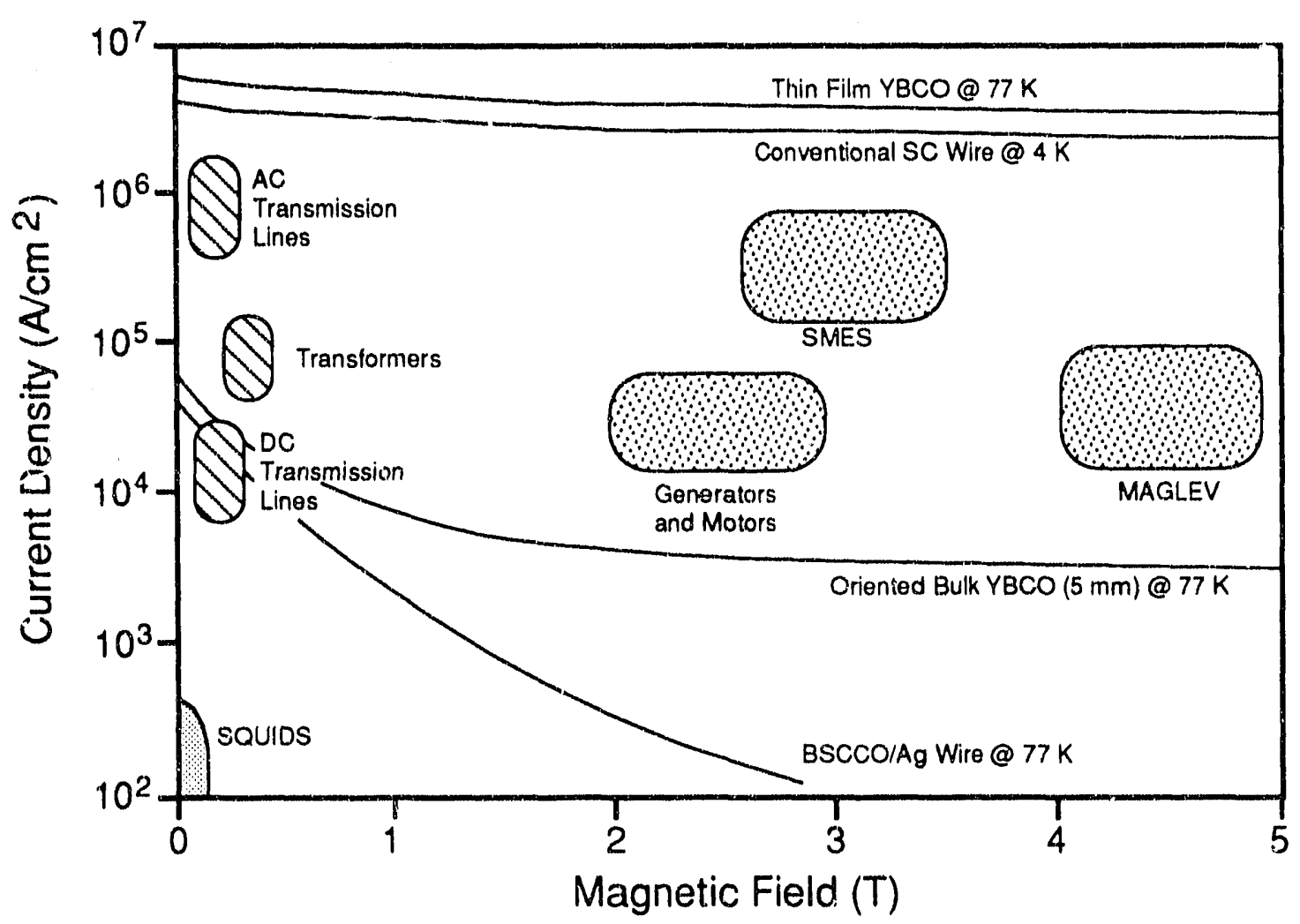

FIGURE 5 Critical Current Density as a Function of Magnetic Field for State-of-theArt Superconductors, Showing Requirements for Various Applications

magnets indicates that a $\mathrm{J}_{\mathrm{C}}$ of $10^{4}$ to $10^{5} \mathrm{~A} / \mathrm{cm}^{2}$ is necessary to keep the conductor volume practical. This $\mathrm{J}_{\mathcal{C}}$ must be available at the operating magnetic field of about $3 \mathrm{~T}$ (or higher). Thin films of HTS have already demonstrated these $J_{C}$ values at high field strengths, proving that such performance is theoretically possible. ${ }^{12}$ However, the production of long lengths of wire by thinfilm processes is not yet known to be feasible.

Typical state-of-the-art values for $\mathrm{J}_{\mathrm{c}}$ at $77 \mathrm{~K}$ are several thousand amperes per square centimeter in zero magnetic field and hundreds of amperes per square centimeter in magnetic fields greater than $1 \mathrm{~T}, 13$ These values are for processes that are amenable to eventually producing long lengths of flexible wire with good mechanical strength. Several directional solidification techniques have produced small samples of bulk HTS that approach the I. requirements of levitation magnets. ${ }^{14}$ However, it is not known if these methods can be used to make long lengths of wire in a reasonable period of time.

An alternative approach may be to operate the superconducting magnets at temperatures below $77 \mathrm{~K}$. BSCCO wire has already demonstrated performance superior to that of LTS wire in very high magnetic fields at $4 \mathrm{~K},{ }^{15}$ and many researchers feel confident that practical HTS wire with satisfactory performance at temperatures up to about 20 or $30 \mathrm{~K}$ can be developed. At $20 \mathrm{~K}$, the refrigeration power required is approximately four imes that at $80 \mathrm{~K}$, but it is still about a factor of 10 lower than the power required at liquid-helium temperature. Of course, at $30 \mathrm{~K}$, pool 


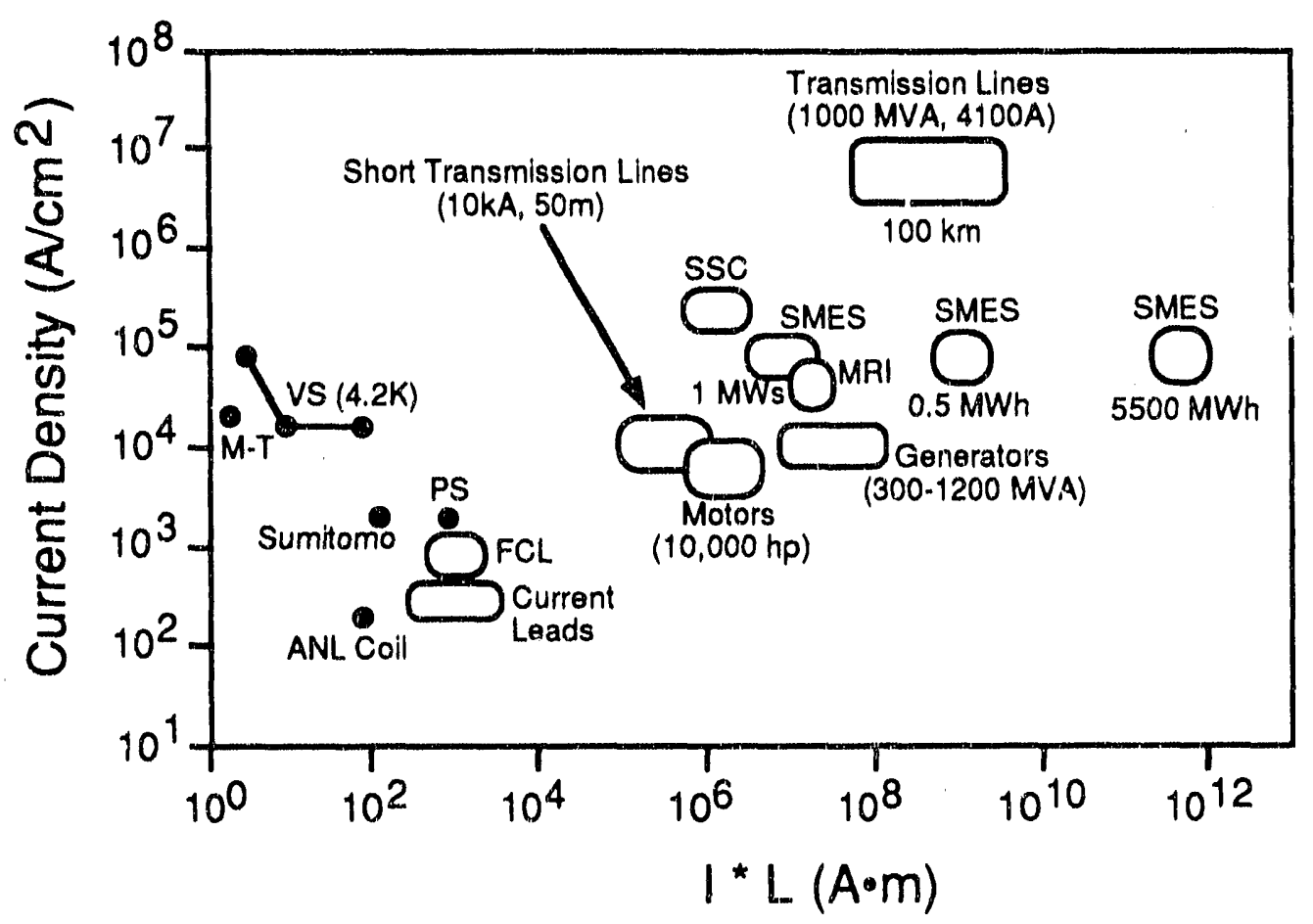

FIGURE 6 Critical Current Density as a Function of Volume Performance Factor for State-of-the-Art Superconductors, Showing Requirements for Various Applications ( $T=77 \mathrm{~K} ; H=0$, except where noted)

boiling in liquid nitrogen is no longer possible, and other means of cooling the HTS must be developed. This alternative approach for maglev transportation is discussed further in Section 3.6.

On the basis of these observations, it is concluded that before significant HTS applications become available at $77 \mathrm{~K}$, significant advances in HTS technology must be made. The state of the art is summarized in Figures 5 and 6 . The next section discusses specific technical problems that will need to be solved to produce large lengths of useful HTS wire.

\subsection{Technical Challenges of HTS Technology}

Most of the technical challenges of HTSs involve increasing the critical current density. A separate problem, typical of all ceramics, is that the materials are intrinsically brittle. Also, each of the different materials has its own unique technical problems. For example, YBCO has difficulty passing current from one superconducting grain to the next. Melt texturing overcomes this problem but so far has been demonstrated only in short samples; the processing time is too long at present to consider making long lengths of wire by this method. The BSSCO family does not have this problem but instead seems to experience an intrinsic weakness in preventing the flow of magnetic flux through it at temperatures much above $30 \mathrm{~K}$. Most of the TBCCO phases also seem to suffer from this flux-flow problem. 


\subsubsection{Weak LInks}

Almost all superconducting materials consist of individual grains or fibers stuck together. At the grain boundaries the material is in the normal state, so the superconducting current must quantum-mechanically tunnel through the boundary from one grain to the next. In the common low- $\mathrm{T}_{\mathrm{c}}$ metallic superconductor $\mathrm{NbTi}$, this is not a problem because the superconducting coherence length is several orders of magnitude greater than the grain boundary thickness, and the attenuation at each boundary is negligible. For HTSs, the coherence length is about $3 \mathrm{~nm}$, approximately the same length as the grain boundary thickness. In the ceramic composite, the result is a network of good superconducting grains connected by these barriers, known as weak links. Any sort of contamination or improper processing can produce larger grain boundaries, and one of the goals of the materials development of HTSs is to make exceptionally clean and thin grain boundaries.

One way to minimize the problem of weak links is to align the individual grains; consequently, a number of processes have been investigated to achieve this end. Alignment is important because of the anisotropic nature of HTSs. With all of the copper oxide planes aligned, it is easier to pass current from one grain to the next. Because the BSSCO material is a micaceous compound and shears readily along certain planes, it is relatively easy to align when the material is rolled. This has been most readily achieved in a powder-in-tube fabrication process, where the HTS powder is sealed inside a silver tube. The tube then undergoes a series of reduction steps, either by drawing, swaging, or rolling, accompanied by heat treatment according to different schedules.

In the YBCO compound, the only method that has yielded substantial alignment is melt texturing, in which the material is solidified in a temperature gradient. In the presence of a temperatlire gradient, growth in one of the crystallographic directions is significantly faster than in the other directions. However, because the rate at which the grains grow is limited, this method is very slow and probably not appropriate for making long lengths of wire.

\subsubsection{Flux-Flow Resistance}

When a superconducting wire is operated in a magnetic field or is used to carry a current that produces a magnetic field, magnetic flux will penetrate the superconductor. The combination of current through the wii 9 and magnetic field perpendicular to the current produces a Lorentz force that tries to push the magnetic flux lines through the superconductor. To prevent electrical resistance in the superconductor, these flux lines must be immobile (i.e., pinned in place). If the flux lines move in response to the Lorentz force, work is done on the flux lines, and energy dissipation and heating occur. High-current-density magnets can experience severe heating, often leading to destruction.

Flux pinning is one of the least understood aspects of HTSs. However, it is believed that thermal noise in the superconductor can depin flux lines, and the higher the operating temperature, the more thermal noise is present. For low- $\mathrm{T}_{\mathrm{c}}$ superconductors, flux flow was a minor irritation because the thermal noise was so low. At $77 \mathrm{~K}$, the thermal noise is about 20 times higher than at $4 \mathrm{~K}$, and the problem is more severe. The various HTS materials appear to suffer from this 
problem to different extents. Figure 7 shows the temperature at which flux flow becomes a problem as a function of magnetic field. Practically speaking, for a fixed temperature, it is unlikely that large current densities can be obtained for magnetic fields greater than those indicated in the figure. As can be seen in Figure 7, YBCO suffers almost no flux-flow problems until either the critical temperature or critical magnetic field is reached. From a flux-flow viewpoint, YBCO is an ideal material. If the weak-link problem could be solved in YBCO, it would be the material of choice.

In addition to YBCO, only certain members of the TBCCO family appear to have the potential, from a flux-flow viewpoint, to achieve useful magnetic field strengths at temperatures in the vicinity of $77 \mathrm{~K}$. Unfortunately, TBCCO seems to react with silver, and the powder-in-tube methods that were successful in aligning individual grains in BSSCO need to be modified for TBCCO. In addition, it is not yet known whether TBCCO will suffer from weak l'nks; however, there is some evidence suggesting that it will not.

\subsubsection{Mechanical Strength}

For a conductor to be useful in practice, it must withstand appreciable mechanical stress. Normal use may require thermal cycling, repeated strain (during fabrication and operation), and consistent behavior over long lengths.

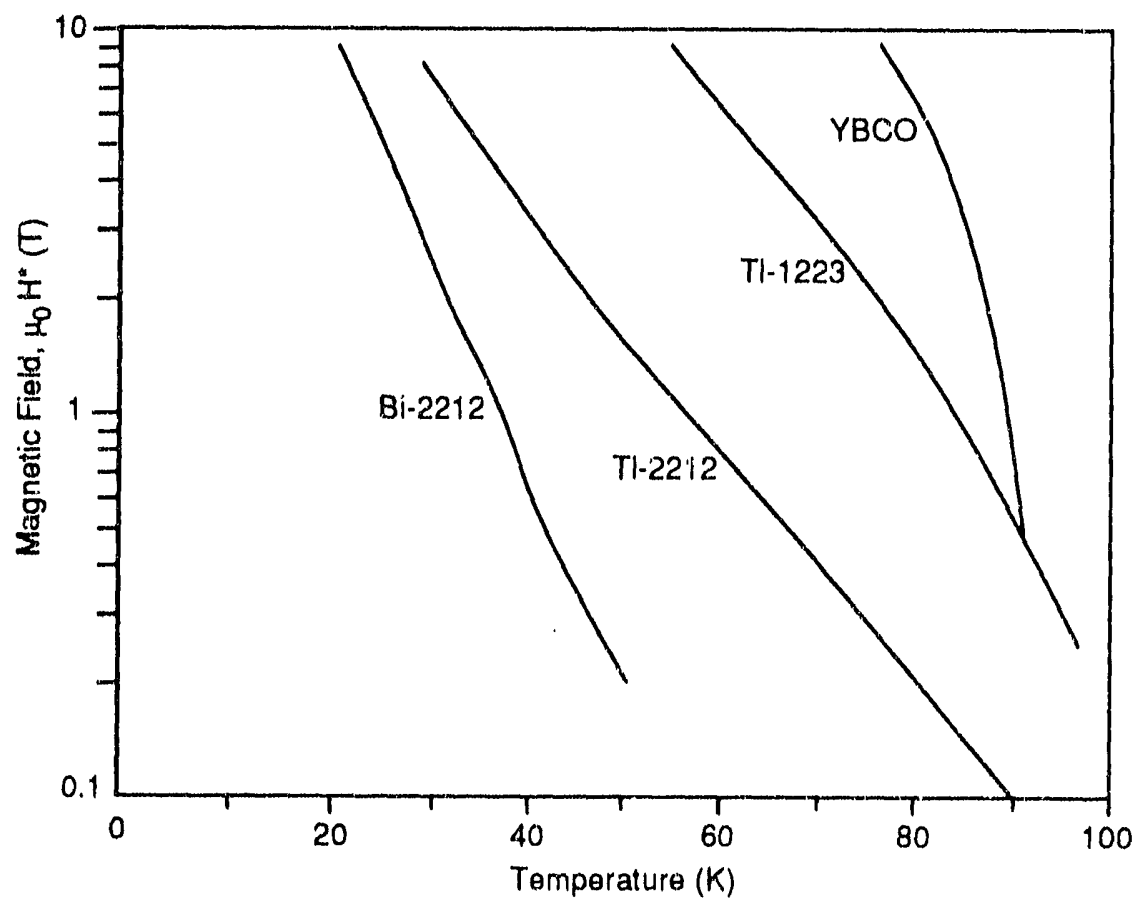

FIGURE 7 Magnetic, Field as a Function of Temperature for Several HTSs, Denoting the Boundary at which Flux-Flow Problems Occur (Courtesy of K. Gray, ANL) 
Ceramic materials are well-known for their brittleness. Clearly, if a crack develops in an HTS wire, the current will no longer be able to flow. Researchers have found that the addition of silver to the HTS powder at the early stages of fabrication improves tensile strength and fracture toughness. Flexural strength of YBCO is now over $200 \mathrm{MPa}$, and the fracture toughness is as high as $4.5 \mathrm{MPa} \cdot \mathrm{m}^{1 / 2}$. This gives the HTS about the same toughness as a ceramic spark plug. Even with these high values, one cannot take the HTS and bend it into a magnet form after it is fired. Considerable improvements must occur before this can happen.

One solution to the brittleness problem is to wind the magnet coil in the green state and then react it in the heat-treatment stage. This was done with the intermetallic compound $\mathrm{Nb}_{3} \mathrm{Sn}$, one of the two most commonly used low- $\mathrm{T}_{\mathrm{c}}$ compounds, which is also brittle like a ceramic.

A second solution is to form the superconductor into fine filaments. If the diameter is small enough, the fibers can be bent to a very small radius after they are fired. So far, the fine filaments of HTS produced by such processes have not yielded very high critical current densities. However, the powder-in-tube method is capable of producing thin tapes. This is clearly an area where more development is needed.

\subsubsection{Thermal-Magnetic Stabllity}

An important characteristic of any magnet is its stability (i.e., its ability to remain in the superconducting state even when exposed to outside disturbances). If any part of a superconductor makes the transition into the normal state, that part will immediately begin to experience joule heating. Unless the magnet system is carefully designed, the temperature of the magnet will rise, often leading to the entire magnet reverting to the normal state. This process is called a quench. In most cases, the magnetic energy stored in the magnetic field will be almost completely dissipated in heating the magnet. If the amount of magnetic energy stored is large, the resulting large temperature rise may damage the magnet in some way. A quench may result when enough energy is deposited in a volume of superconductor to raise its temperature above the critical value. A variety of energy disturbances may perturb the system, but the most common for LTS magnets are frictional heating due to conductor motion and release of elastic energy due to breakage of filaments or other structural components.

A conductor carrying current in a magnetic field experiences a Lorentz force proportional to the current and the magnetic field strength. If unconstrained, the conductor moves until it is no longer in the magnetic field. If the conductor is constrained so that it moves only a finite distance in the magnetic field, its motion against the constraint results in frictional heating. The work done (i.e., the heat energy deposited in the conductor) is directly proportional to the distance moved and the Lorentz force. Thus, the specific energy, W, deposited is given by

$$
\mathrm{W}=\mathrm{JB} \delta \text {, }
$$

where $\mathrm{J}$ is the current density in the conductor, $\mathrm{B}$ is the magnetic field through which the conductor moves, and $\delta$ is the distance moved. 
When a magnet is energized, forces exist that try to push the conductors apart. The conductors and structural members that are used to hold the magnet together are thus under pressure. To the first order, this pressure is proportional to the square of the magnetic field with a $\mathrm{B}$ value of $1 \mathrm{~T}$ equivalent to about $0.4 \mathrm{MPa}(60 \mathrm{psi})$ of pressure. As the magnet is energized, the structural members experience a stress, and energy is put into the system as elastic energy of strain, the amount of energy per unit volume being proportional to the square of the pressure and inversely proportional to the elastic modulus $\mathrm{E}$. If any structural components break, a significant fraction of the elastic energy is released as heat when the strain of the broken material is alleviated.

An advantage of an HTS over an LTS is that magnets operating at $77 \mathrm{~K}$ are less likely to quench than those operating at $4 \mathrm{~K}$. (This greater stability is a result of the higher heat capacity of materials at $77 \mathrm{~K}$ compared with that at $4 \mathrm{~K}$.) A comparison of the two temperatures of operation is shown in Figure 8. For comparison the sensible heat capacity of conductors and latent heat and sensible heat capacity of cryogenic coolants are shown. The temperature rise for a given energy input is shown for typical conductors initially at $4 \mathrm{~K}$ or $77 \mathrm{~K}$.

A conciderable amount of effort has been devoted over the years to designing LTS magnets that do not quench. For an LTS, the critical tempurature at operating current density and magnetic

$\frac{\text { Heat Capacity Latent Heat }}{\mathrm{J} / \mathrm{m}^{3} \mathrm{~K}}$
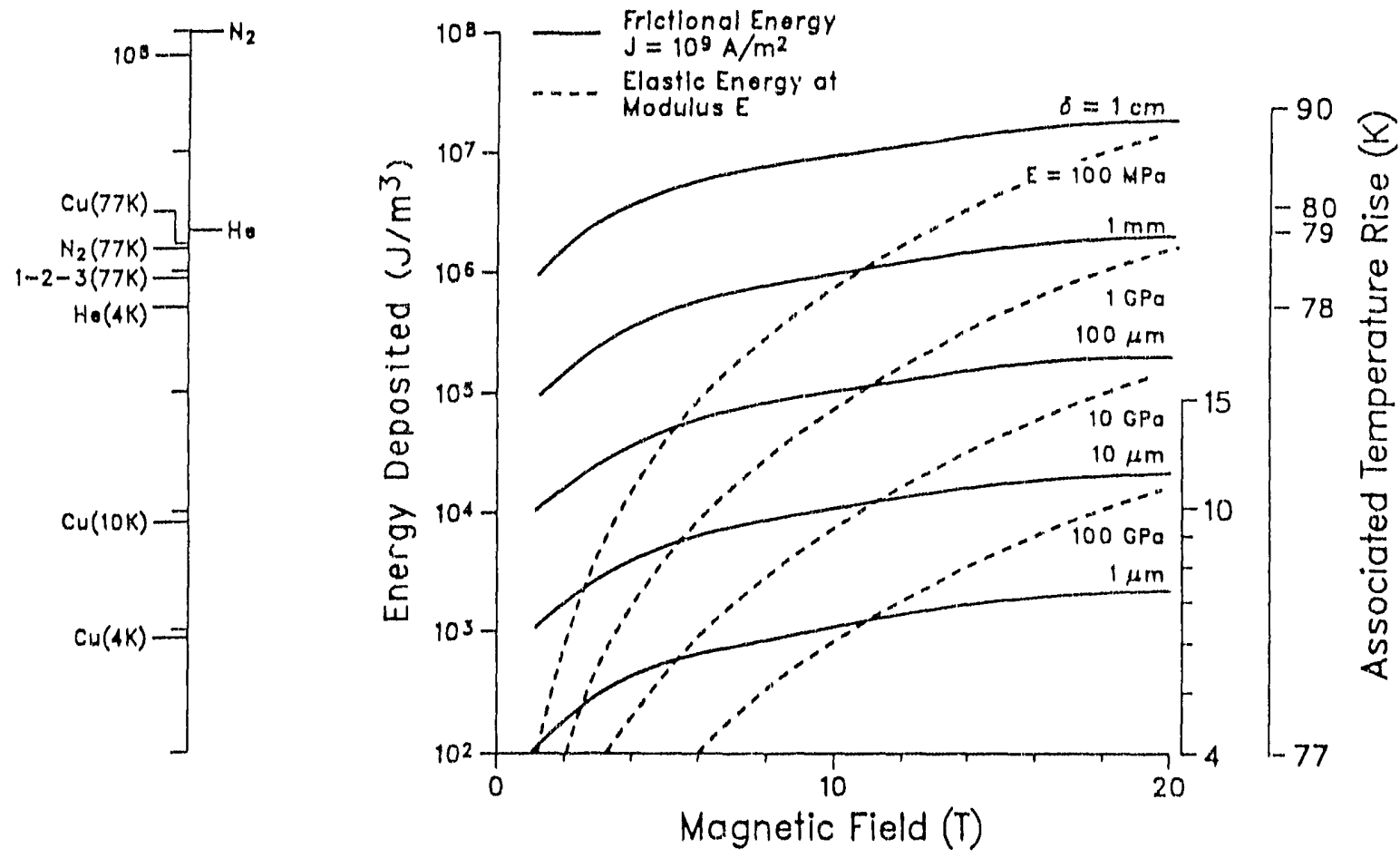

FIGURE 8 Specific Energy for Frictional Heating and Cracking Disturbances as a Function of Magnetic Field Strength with Comparison of Specific Heat, Latent Heat, and Conductor Temperature Rise 
field strength is typically only a few degrees above the 4-K temperature of liquid helium, and magnet designs have evolved to limit temperature excursions with allowed energy perturbations of about $10^{4} \mathrm{~J} / \mathrm{m}^{3}$ or less. As seen in Figure 8, if the same designs can be used to limit energy perturbations to the same amount at $77 \mathrm{~K}$, then the traditional spectrum of disturbances will result in an insignificant temperature rise. Thus, HTSs should be much more stable than their lowtemperature counterparts.

Tolerance of temperature excursions of several degrees appears likely in the new ceramic superconductors. One outcome of this tolerance could be a relaxation of design constraints (e.g., allowing more motion in the conductors or using structural members with a lower elastic modulus). A second possibility may be that the ceramic superconductors can be used in magnets that reliably operate at much higher magnetic field strengths without quenching.

The above arguments are made by simplistic extrapolation of experience with LTS magnets to a higher operating temperature. The conclusions must be tempered with the observation that other design constraints (such as those due to brittleness of the ceramic superconductor) may be present and either constrain the design or require operation at lower maximum magnetic field strength. Such design issues can only be discovered by analysis of and experiments with HTS magnets.

Operation at liquid-nitrogen temperatures is a new regime for superconductor stability, and so far, only preliminary estimates have been made of the impact. ${ }^{16}$ Heat capacities at $77 \mathrm{~K}$ are two to three orders of magnitude larger than at $4 \mathrm{~K}$. The available heat flux for pool-boiling in liquid nitrogen is about ten times higher than that available in liquid helium. The electrical conductivity of possible normal metal stabilizers is lower, although the magnetoresistance is comparable and may dominate for large-field devices. Experience with LTS magnets suggests that the consequences of these parameter changes are such that the probability of a quench is greatly reduced. However, if a normal zone does develop in part of the magnet, it will be very difficult for the normal zone to propagate quickly, and a likely scenario is the development of a local hot spot, followed by destruction of the magnet. Therefore, the combination of these parameters may require conductor geometries and magnet protection schemes considerably different from those developed for LTSs.

\subsection{Near-Term Applications}

As shown in Figures 4-6, there are already several applications for which today's HTS materials are useful. A cryostat current lead connects a power source at ambient temperature to a cryogenic device, usually at liquid-helium temperature. With normal metal leads, the joule heating and thermal conduction bring substantial amounts of heat into the cooling medium of the device, and refrigeration energy must be expended to remove this heat and keep the device cold. If an HTS is used for the colder part of the lead, for example, from $77 \mathrm{~K}$ to $4 \mathrm{~K}$, then there is no joule heating. The ceramic superconductors have much lower thermal conductivity than normal metals, so the quantity of conducted heat can be made very low, even with relatively short lengths of HTS leads. The leads typically do not operate in high magnetic fields, and they can be shielded with conventional high-permeability shields. Low current densities, from 100 to $1000 \mathrm{~A} / \mathrm{cm}^{2}$, can be 
used in these leads, and such current densities are available with today's materials. An HTS lead has already been demonstrated that superconducts $2000 \mathrm{~A}$ and reduces the helium boil-off to about half that of the best conventional current leads. 17 Such leads may have application to levitation magnets and to superconducting magnetic energy storage coils in inaglev applications.

Superconducting bearings are also possible with today's HTS materials. In this application, levitation pressure can be achieved from the magnetization within individual grains cf the HTS. There is no need to transport current from grain to grain, so weak links are not a problem. Levitation pressure increases as the grain size increases, and the best levitation pressure would result from a large single crystal or a polycrystalline sample, where the transport current was as high as the current within the grains. Howevar, grains several millimeters in diameter have been made with the YBCO compound, and this is large enough to achieve useful levitation pressures. Simple prototype bearings have already been demonstrated with levitation pressures of almost $10^{5} \mathrm{~Pa}(15 \mathrm{psi}){ }^{18}$ In addition, HTS bearings can be constructed that demonstrate very low rotational drag. 19 Coupled with the available pressure, the low drag enables very highefficiency flywheels to be technically feasible.

A related potential application, suggested by Wipf and Laquer, is to treat the magnetized HTS as a permanent magnet. ${ }^{20}$ So far, the remanent magnetization for HTS materials is considerably less than a tesla. However, the flux-jump field at $77 \mathrm{~K}$ is about $6 \mathrm{~T}$, which implies that a remanent field of $3 \mathrm{~T}$ could exist. ${ }^{20}$ This application may eventually become feasible as HTS materials improve.

\subsection{Intermediate-Term Applications}

Stveral intermediate-term HTS applications, indicated in Figures 4-6, should be available by the time a maglev transportation system is built in the United States. Superconducting transmission lines should be available that transmit substantial amounts of current in low magnetic fields over relatively short distances (i.e., less than about $100 \mathrm{~m}$ ). HTS fault-current limiters should also be available for several current and power ranges. 


\section{Potential Areas of Impact for Maglev Trans,jortation}

In all maglev system designs, the guideway accounts for the major fraction of the total cost. However, the superconductor plays an important role in determining the overall cost, although its cost is only a small fraction of the vehicle cost. Because HTS magnets are relatively lightweight comparec with conventional electromagnets, the vehicle can carry more passengers, and because the superconductor produces larger magnetic fields than do normal conductors, there can be a greater clearance between the vehicle and the guideway. This raises the possibility of a less expensive guideway. Thus, the availability of high-temperature superconductors is expected to increase the number of possible maglev design alternatives. At present, no detailed design studies of maglev systems using HTSs have been made. This section presents several concepts that could be considered in such studies.

\subsection{Liquid-Nitrogen-Cooled Superconducting Magnets}

One of the more obvious design alternatives is simply to swap the high-temperature superconducting coils for their low-iemperature counterparts and exchange liquid nitrogen for liquid helium. The possible use of HTSs in levitation and propulsion magnets cooled by liquid nitrogen is probably the most obvious and advantageous application of HTS materials in maglev transportation systems. Production and refrigeration of liquid nitrogen is relatively straightforward and reliable. It can often be accomplished with a single-stage refrigerator. Refrigeration of liquid helium is considerably more complicated, with more than two stages usually required. The Carnot efficiency of removing heat at $77 \mathrm{~K}$ is about 20 times higher than that of removing heat at $4 \mathrm{~K}$. At $4 \mathrm{~K}$, attainable efficiencies relative to Carnot are typically half that at $77 \mathrm{~K}$, so refrigeration of liquid helium is more than 20 times as expensive as refrigeration of liquid nitrogen. Probably the increased reliability of operating with liquid nitrogen is the most appealing feature of this design.

A secondary, but important, issue is that helium is a relatively scarce resource. ${ }^{21}$ The present price of liquid helium is artificially low in the United States because helium is found in relative abundance in a few natural gas wells. The price is not expected to remain this low in the years to come. Nitrogen, on the other hand, is the major constituent of the Earth's atmosphere. Its abundance and ease of liquefaction will make it inexpensive for many years. Whereas cost might dictate ti.s need to save helium on board a maglev vehicle, heated nitrogen could be discarded. This would eliminate the need for on-board helium storage vessels (at high pressure) or reliquefaction equipment.

Liquid-nitrogen-cooled HTS magnets are not yet developed, and for near-term maglev considerations, one cannot count on their availability. Although there is no guarantee that they will ultimately be available, the present efforts in HTS development give most researchers in this area considerable optimism. 


\subsection{Shlelding}

One of the major concerns ior maglev transportation is the possible effect of electromagnetic fields on the passengers. At present, the environmental effects of these fields are not well-known; however, they could certainly play an important role in determing which maglev concept is chosen for system development in the United States.

Conventional magnetic shielding uses ferromagnetic material. To achieve a substantial reduction of magnetic field in systems using superconducting levitation magnets, considerable shield weight must be added to the vehicle. It may be possible to use HTS materials, which can be almost completely diamagnetic up to fields approaching $1 \mathrm{~T}$, to shield the passenger compartment. In principle this can be done with only a small weight penalty to the magiev vehicle. The state of the art is such that these kinds of materials are not available at present; however, they may become available as research into materials properties continues to improve HTSs.

\subsection{Superconducting Magnetic Energy Storage for Waysicie Power}

Superconducting magnetic energy storage (SMES) offers important benefits in maglev systems. The major concept is that power is used to charge the SMES system during times of low electrical demand; then the SMES system is discharged during times of high demand. Because peak power is usually considerably more expensive than base-load power, the use of stored energy has great potential to reduce energy costs. The value of SMES is that because of the superconducting current, the SMES system is very efficient at storing energy on a diurnal basis. Maglev systems often have peak power requirements when propelling the vehicles during certain parts of the trip. Using a SMES system has the potential to reduce the electrical costs of the system.

Researchers at the Paul Scherer Institute are at present investigating a relatively small SMES to be incorporated into the Swiss railroad system. This magnet will be cooled by liquid helium. The problem with a helium-cooled SMES system is that refrigeration power can greatly reduce efficiency in small units. If HTS conductors could be used in SMES, the demand for this type of energy storage would increase.

The power leads constitute a large fraction of the total refrigeration requirements. Thus, there is considerable interest in attaching HTS current leads to liquid-helium SMES systems. It is believed that the Swiss are exploring this option. If the HTS leads are successful, the demand for SMES systems will increase.

\subsection{Flywheels for Wayside Power}

As mentioned earlier, HTS bearings can be used to make very efficient flywheels. Flywheels could be used to provide wayside storage in the same way that SMES systems could. There are no technical barriers preventing the success of this technology; however, the cost of these devices could ultimately be an issue. 


\subsection{Downleads to Continuously Powered Magnets}

HTS current leads could be used to power helium-cooled levitation magnets. Most present designs run these magnets in persistent-current mode with the leads removed or unenergized to reduce heating in the liquid-helium coolant. HTSs allow the magnets $(0)$ be continuously energized without undue heat transfer to the liquid helium. This option could have importance in quench protection and, perhaps, in control of ride quality.

\subsection{Liquid-Hydrogen-Cooled Magnets}

In the next several years, high-temperature superconducting wire with good properties at temperatures up to $20 \mathrm{~K}$ will probably become available. One conceptual study has indicated that there may be an advantage in using liquid hydrogen aboard the vehicle to power the turbine/generator that propels the train, because the liquid hydrogen could also be used to cool the levitation magnets. 22 A schematic diagram of this system is shown in Figure 9.

This maglev concept uses electrodynamic suspension in which repulsive levitation forces are produced between superconducting magnets aboard the vehicle and "image magnets" produced by eddy currents induced in a conducting guideway by the moving superconducting magnets. As is typical of this method, inherently stable levitation can be achieved with relatively large guideway clearance, but conventional means of support must be used at low speeds. The major advantage realized by the large clearance is larger tclerance values in the guideway, resulting in lower capital and maintenance costs.

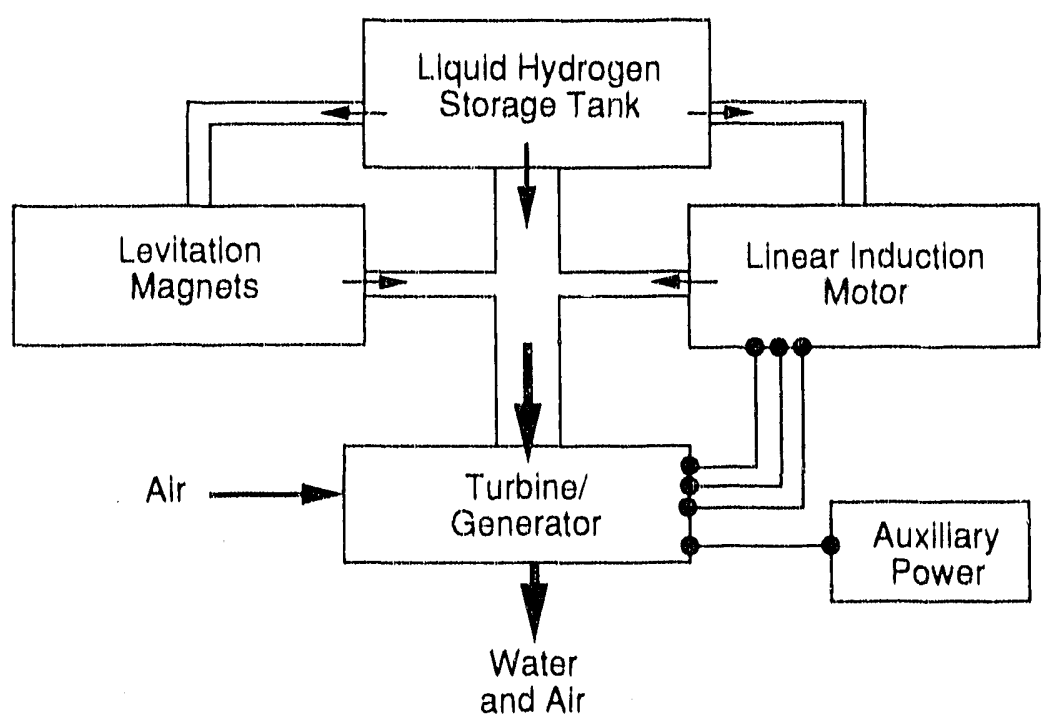

FIGURE 9 Schematic Dlagram of Fluld and Electricity Flow in the Liquid-Hydrogen Maglev System 
The vehicle lev،.ation magnets are made from liquid-hydrogen-cooled high-temperature superconductors operating in persistent-current mode. A large storage tank of liquid hydrogen is on board, but no refrigerator is present. The vehicle is propelled by a short-"tator, single-sided, linear inducion motor (LIM) or a short-stalor, homopolar, synchronous motor (LHSM) that interacts with the guideway. Electrical power is provided to the LIM or to the LHSM from an airbreathing liquid-hydrogen turbine that drives a generator. The guideway is supported by a concrete structure and is divided into a levitation part, which consists of a coninuous aluminum sheet, and a separate propulsion part, which consists of a continuous aluminum sheet backed by an iron strip.

The flow of fluids in the system is shown schematically in Figure 9. Small amounts of liquid hydrogen flow as needed from the storage tank to cool the levitation magnets and the windings of the motor and generator. After cooling these components, the hydrogen passes into the turbine and combust: with ambien air to provide the motive force for the turbine. Usually, the amount of hydrogen required for propulsion is larger than that required for cooling, so the bulk of the hydrogen flow to the turbine is provided by a direct line. The turbine exhaust consists mainly of water and oxygen-deplcted air. 


\section{Conclusions}

High-temperature superconductors should eventually have a substantial impact on maglev transportation. Areas identified for possible impact on maglev technology are (1) liquid-nitrogencooled levitation magnets, (2) magnetic field shielding of the passenger compartment, (3) superconducting magnetic energy storage for wayside power, (4) superconducting bearings for flywheel energy storage for wayside power, (5) downleads to continuously powered liquidhelium-cooled levitation magnets, and (6) liquid-hydrogen-cooled levitation magnets and linear motor propulsion windings. The use of HTS current leads may have an impact in the near term. Major technical issues that remain to be resolved for the use of HTSs in maglev applications include thermal magnetic stability, mechanical properties, and critical current density al quidnitrogen temperatures. 


\section{References}

1. Johnson, L.R., tut al., 1989, Maglev Vehicles and Superconductor Technology: Integration of High-Speed Ground Transportation into the Air Travel System, Report ANL/CNSV-67, Argonne National Laboratory, Argonne, Ill.

2. Rote, D.M., et al., 1989, Applications of Superconductor Technologies to Transportation, Report ANL/CNSV-68, Argonne National Laboratory, Argonne, Ill.

3. Rowell, J. (editor), 1991, "High-Temperature Superconductivity," Physics Today $44(6): 22-82$, June.

4. Wilson, M., 1983, Superconducting Magnets, Oxford Press, Oxford, England.

5. Wu, M.K., et al., 1987, "Superconductivity at $93 \mathrm{~K}$ in a New Mixed-Phase Y-Ba-Cu-O Compound System," Physical Review Letters 58:908-910.

6. Parkin, S.S.P., et al., 1988, "Bulk Superconductivity at $125 \mathrm{~K}$ in $\mathrm{Tl}_{2} \mathrm{Ca}_{2} \mathrm{Ba}_{2} \mathrm{Cu}_{3} \mathrm{O}_{\mathrm{x}}$," Physical Review Letters 60:2539-2542.

7. Maeda, H., et al., 1988, "A New High-T c $_{\text {C }}$ Oxide Superconductor without a Rare Earth Element," Japanese Journal of Applied Physics 27:L209-L210.

8. Sheng, Z.Z., and A.M. Hermann, 1988, "Sliperconductivity in the Rare-Earth-Free Tl-Ba-Cu-O System above Liquid-Nitrogen Temperature," Nature 332:55-59.

9. Cava, R.J., et al., 1988, "Superconductivity near $30 \mathrm{~K}$ without Copper: the $\mathrm{Ba}_{0.6} \mathrm{~K}_{0.4} \mathrm{BiO}_{3}$ Perovskite," Nature 332:814-816.

10. Holczer, K., et al., 1991, "Alkali-Fulleride Superconductors: Synthesis, Composition, and Diamagnetic Shielding," Science 252:1154-1157.

11. Rosseinsky, M.J., et al., 1991, "Superconductivity at $28 \mathrm{~K}$ in $\mathrm{Rb}_{\mathrm{x}} \mathrm{C}_{60}$," Physical Review Letters 66:2830-2837.

12. Mankiewich, P.M., et al., 1987, "Reproducible Technique for Fabrication of Thin Films of High Transition Temperature Superconductors," Applied Physics Letters 51:1753-1755.

13. Shi, D., et al., 1989, "A Superconducting Coil Made of Filamentary Composites," Materials Letters $9: 1-4$.

14. Salama, K., et al., 1989, "High Current Density in Bulk $\mathrm{YBa}_{2} \mathrm{Cu}_{3} \mathrm{O}_{\mathrm{x}}$ Superconductor," Applied Physics Letters 54:2352-2354. 
15. Heine, K., et al., 1989, "High-Field Critical Current Densities in $\mathrm{Bi}_{2} \mathrm{Sr}_{2} \mathrm{Ca}_{1} \mathrm{Cu}_{2} \mathrm{O}_{8+\mathrm{x}} / \mathrm{Ag}$ Wires," Applied Physics Letters 55:2441-2443.

16. Iwasa, Y., 1988, "Design and Operational Issues for 77-K Superconducting Magnets," IEEE Transactions on Magnetics MAG-24:1211-1214.

17. Wu, J.L., et al., 1991, "Design and Testing of a High Temperature Superconducting Electrical Lead," IEEE Transactions on Magnetics 27:1861-1865.

18. Weinberger, B.R., et al., 1990, "Magnetic Bearings Using High Temperature Superconductors: Some Practical Considerations," Superconductor Science and Technology 3:381-388.

19. Weinberger, B.R., et al., 1991, "Low Friction in High Temperature Superconducior Bearings," Applied Physics Letters 59:1132-1134.

20. Wipf, S.L., and H.L. Laquer, 1989, "Superconducting Permanent Magnets," IEEE Transactions on Magnetics 25:1877-1890.

21. Hull, J.R., and G. F. Berry, 1988, "Advantages of High-Temperature Superconductivity in Large-Scale Applications," ASME Winter Annual Meeting, MD-Vol. 11, pp. 1-7, Chicago, Ill., Nov.-Dec.

22. Hull, J.R., and J. He, 1991, "Maglev System Concept Using 20-K High-Temperature Superconductors and Hyperconductors, "Proceedings of the Intersociety Energy Conversion Engineering Conference, Vol. 4, pp. 570-575, Boston, Mass., August. 

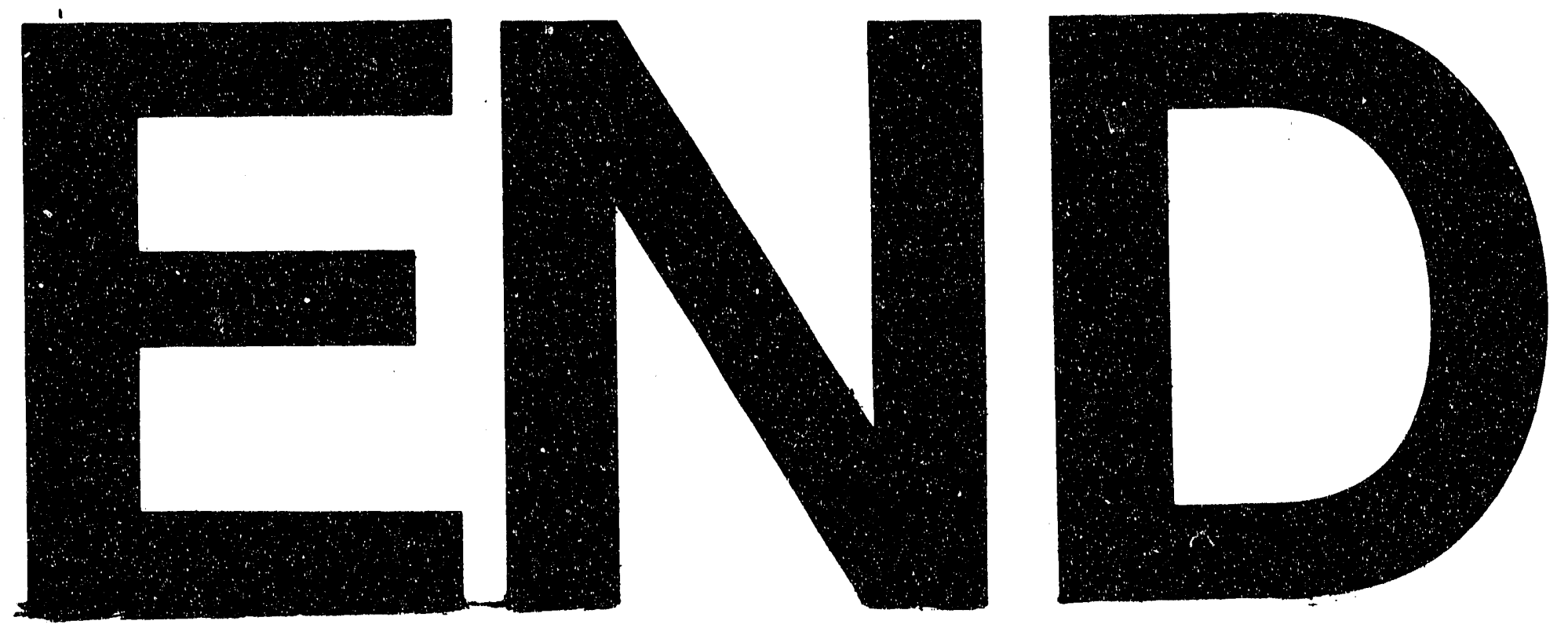

F..........
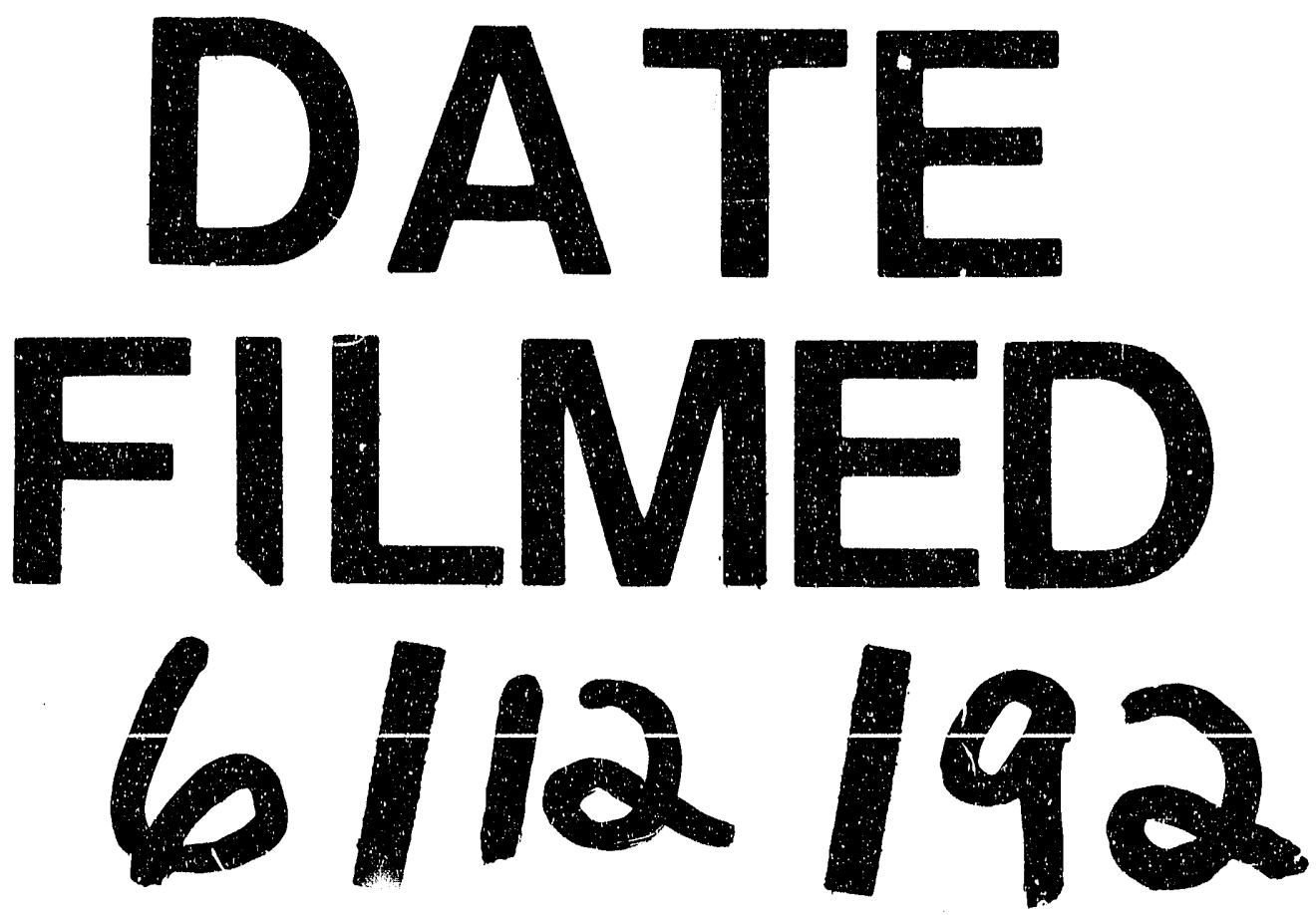
